\title{
The effectiveness of lifelong learning policies on youth employment: do regional labour markets matter?
}

\author{
Queralt Capsada-Munsech and Oscar Valiente
}

\section{Introduction}

In a context of historical growth of youth unemployment rates due to the global financial crisis, most of the lifelong learning (LLL) policies adopted by national governments across Europe have been dominated by the employability agenda. The problem with this agenda is that it assumes that the main causes of youth unemployment are to be found in the education and training system and in the inadequate level of skills of young people, without questioning the economic and labour market policies that have led to the youth unemployment crisis. In this sense, LLL policies contribute to turn a structural economic problem into an individual one, usually of an educational nature (Biesta, 2006). These LLL policies construct their target groups as individuals with educational deficits or without the skills demanded by the labour market. Consequently, the policy solutions offered to these individuals are additional work-relevant education and training opportunities, preferably delivered through work-based learning modes of provision.

Most of the LLL policies analysed in this research can be classified into two main groups: apprenticeships and employability training courses. While apprenticeships aim at providing work-based learning to gain industry- and/or firm-relevant skills, employability courses aim at activating unemployed youth and preparing them for the demands of the world of work. In both cases, there is a strong focus on meeting the skills demanded by employers, which vary across regions due to their different labour market and socioeconomic configurations.

Education and training institutions, as well as most LLL policies, are designed and promoted at the national level. Nevertheless, their enactment and implementation takes place at the regional and/ 
or local level. Given the heterogeneity of socioeconomic contexts within countries, the effectiveness of these national policies is likely to be moderated by the regional labour markets and the employment opportunities available to young adults in each context. The aim of this chapter is to analyse and discuss to what extent the effectiveness of national LLL policies on youth employment varies across regions displaying different regional labour market demands and employment opportunities for young adults in vulnerable situations.

\section{LLL policies and the employability debate}

The notion of employability is highly contested and controversial both at a theoretical and political levels. Perhaps the most widely used definition of employability is the one that focuses on the ability of individuals to access a job, to retain this job, to move between different roles within the same organisation and to access new jobs (Hillage and Pollard, 1998). Under this definition, employability does not refer so much to the fact of being employed in a specific moment of time, but to the ability of individuals to be employed during the course of their professional careers.

The theoretical approaches that have tried to put this concept into operation can be differentiated between those that focus on supply-side factors, and those that focus on demand-side factors (McQuaid et al, 2005). On the one hand, supply-focused theories place more emphasis on individual factors of employability, such as attitudes, transversal and transferable skills, qualifications and knowledge of the work environment, the ability to find a job, the adaptability and flexibility of the worker or the status of their health. On the other hand, demandfocused approaches pay more importance to social and labour market factors, the macroeconomic environment, the characteristics of the jobs, recruitment practices, support and guidance, and the effects of other social policies on the living conditions of young people (McQuaid and Lindsay, 2005).

Despite the complexity and nuances of academic debates around the notion of employability, most policy discourses have tended to adopt a very narrow version of the concept, placing all the emphasis on supply-side factors. Due to the 'supply-side fundamentalism' that dominates the policy discourses on employability (Peck and Theodore, 2000), the responsibility to improve the opportunities to be employed falls entirely on the education system and on the individual. Employability discourses tend to point out that the education system does not achieve the minimum levels of quality, that the curriculum is 
too academic, that the skills which are acquired are not relevant for the labour market and that vocational schools and training centres should respond better to the needs of employers. This individualisation and educationalisation of youth unemployment is linked to a LLL policy agenda that promotes new institutional and governance arrangements in the vocational education and training (VET) system to increase the voice and the influence of employers and market mechanisms in the planning and provision of LLL (McGrath et al, 2010). These reforms tend to involve greater decision-making capacity of employers in governing bodies, the use of staff from companies in the training of young adults, less time for theoretical knowledge and more for practical skills in the curriculum, shorter training courses over formal education, and less hours of classroom education and more work-based learning forms of provision.

In this chapter, we go beyond the supply-side fundamentalism that has dominated political discourses in Europe when analysing the relationship between LLL policies and youth unemployment. Instead, we take into account both the supply and labour demand factors - as well as the interaction between them - when analysing the relationship between LLL and youth employment. The educational and training offered, the socioeconomic background of young adults and the labour market conditions are factors that should not be considered in isolation or as independent. Therefore, we need to understand how these factors influence each other in the educational, social and labour market contexts where young adults live and make their decisions.

\section{Contextualisation and selection of cases}

Comparative research on LLL policy has traditionally used the nation state as its primary unit of analysis, distinguishing different national institutional specificities, cultures, traditions and structures in spheres such as education and training or labour market organisation. This literature pointed to several dimensions along which countries vary in terms of institutional design, patterns of relationship between the public and private spheres, funding and support/guidance schemes. Comparative research from a range of disciplines has contributed vastly to coming to terms with this enormous complexity by designing classificatory and typological frameworks that help us to understand different systems as ideal-typical cases, thus yielding interesting insights into the central characteristics and peculiarities of their systems (Allmendinger, 1989; Shavit and Müller, 1998; Ashton et al, 2000; Greinert, 2004; Saar et al, 2013; Pilz, 2016). 
Institutional political economy has tried to integrate the relationships among education, the labour market and economic factors in its classifications from an interdisciplinary perspective. Under this tradition, Busemeyer and Trampusch (2012) contributed with the most accomplished classification of skill formation systems in advanced economies. Taking the paradox of collective action among firms as the starting point (Crouch et al, 2001), they interrogate how institutional arrangements of skill formation facilitate the solution of collective action problems typical of unregulated training markets. They suggest two relevant dimensions of variation to understand the different solutions to these collective action problems in VET: the degree of firm involvement and the degree of public commitment. A higher involvement of firms in training might imply a higher specificity of training, and a higher commitment of the state will go beyond financial support and include the certification and standardisation of training, as well as the recognition of VET as a viable alternative to academic higher education. The combination of these two dimensions results in four types of solutions: (1) the liberal model of on-the-job-training (e.g. the UK); (2) the segmentalist model of firm's self-regulation (e.g. Japan); (3) the statist solution of state-run training (e.g. France); and (4) the collective solution where firms, employers' and workers' associations and the state collaborate in providing and financing skills (e.g. Germany).

We first use aggregate quantitative data at the national and regional levels (NUTS 2) to map countries and regions under study in the YOUNG_ADULLLT research project against the skill formation regimes framework, based on the degree of public commitment and firms' involvement in skill formation in VET. ${ }^{1}$ We operationalise these two dimensions following previous research (Busemeyer and Iversen, 2012):

- Public commitment to VET: we multiply the national public spending in upper secondary education as a share of GDP (gross domestic product) (average 2012-15) with the share of students in upper secondary vocational education (2012) to provide a more refined and proportional measurement of the public spending for VET. ${ }^{2}$ Indicators come from harmonised Eurostat data (Eurostat, 2012a, b).

- Firms' involvement in VET: we use the share of students enrolled in programmes that combine school- and work-based provision of initial VET (typically apprenticeships), based on Organisation for Economic Co-operation and Development (OECD) data (OECD, 2017: 258). ${ }^{3}$ 
Figure 5.1 displays a wide variation across YOUNG_ADULLLT countries in reference to their degree of public investment ( $Y$ axis), firms' involvement in VET (X axis) and the youth unemployment rate (marker's size). ${ }^{4}$ Unsurprisingly, Germany (40 per cent) and Austria (33 per cent) are the ones displaying the largest share of students combining schooland work-based learning, followed by the UK (22 per cent) and Finland (10 per cent). The rest of the countries present comparatively low or zero levels of students enrolled in this kind of programmes. ${ }^{5}$

With regard to the degree of public investment in VET in relation to the number of students, Finland displays comparatively the largest investment, followed by Austria. The remaining countries show a similar public spending in $\mathrm{VET}^{6}$

Mapping the relative position of the nine countries against the four skill formation regimes, Austria can be clearly classified in the collective skill formation regime, while Germany displays the highest degree of firms' involvement, but a more limited public commitment. The UK displays middle levels of public commitment and firms' involvement in VET, while Finland can be clearly positioned in the statist skill formation model. The remaining countries (i.e. Bulgaria, Croatia, Italy, Portugal and Spain) can be classified within the liberal model given the inexistent level of firms' involvement in VET and the low or medium public commitment/investment in VET.

At first glance, Figure 5.1 also suggests a negative association between the youth unemployment rate (marker's size) and the degree of firms' involvement in VET (X axis). This is in line with previous research findings, showing that education systems with early tracking and a vocational orientation facilitate labour market allocation, although they also increase social inequality (Shavit and Müller, 1998; Bol and van de Werfhorst, 2013). Nevertheless, these differences in labour market allocation are not only influenced by educational institutions and characteristics of the VET system, but also by the regional education, training and employment opportunities. Table 5.1 presents an approach to the potential supply and demand of youth's skills across the regions under study, including the share of early leavers from education and training (Eurostat, 2014a), ${ }^{7}$ the share of youth aged 30-34 with higher educational attainment (ISCED 5-8) ${ }^{8}$ (Eurostat, 2014b) and the youth unemployment rate (Eurostat, 2014c). ${ }^{9}$

Overall, data presented suggests a positive association between youth unemployment and the share of early leavers from education and training in the region, and a negative one with the share of higher educated. Although these are not surprising findings, for the purpose of this chapter it is more interesting to take an in-depth look at the variation 


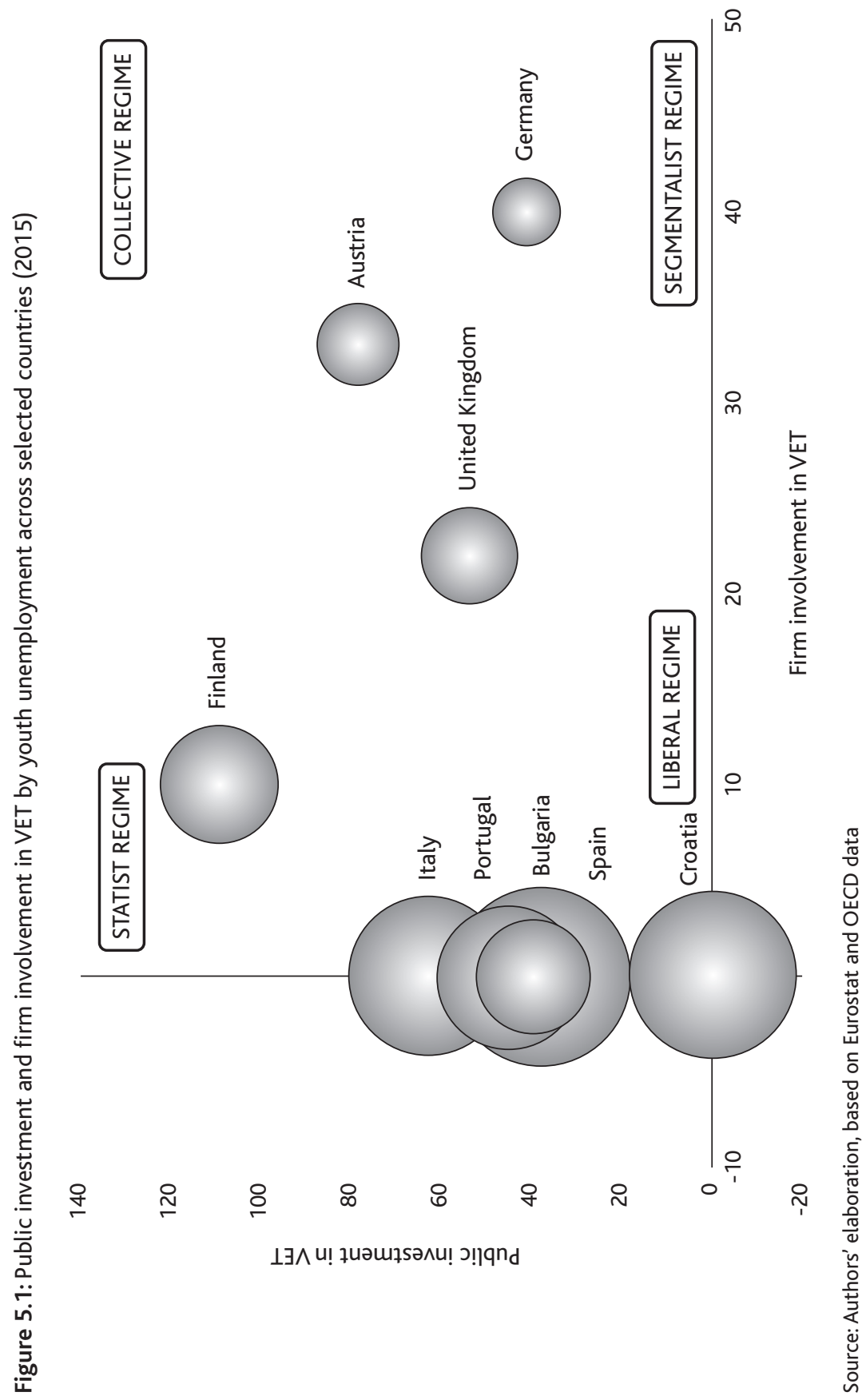


Effectiveness of LLL policies on youth employment

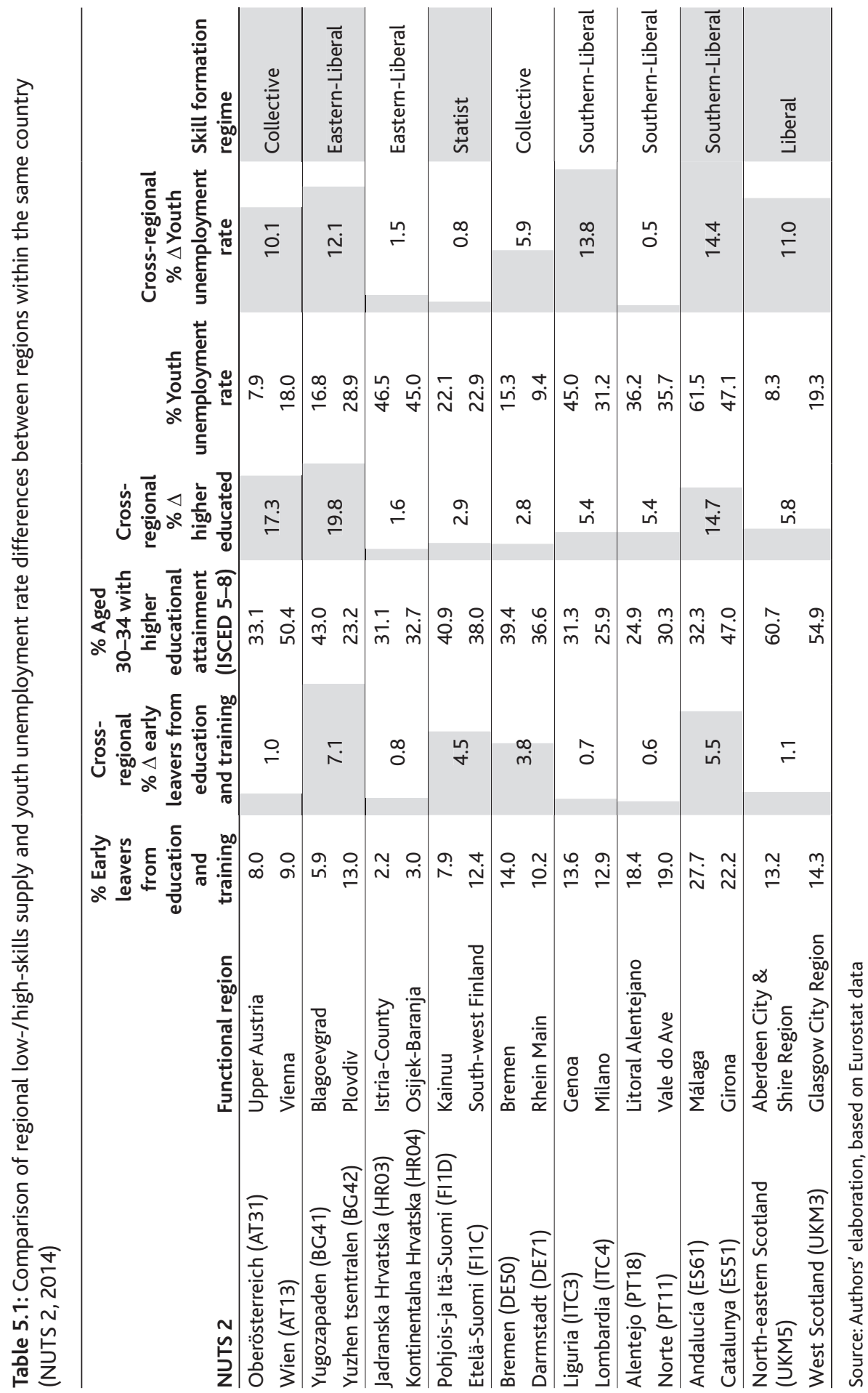


between regions in the same country - which present very similar or identical education and training systems and LLL policies (see Table 5.1). For instance, large differences among regions within the same country are observed in the share of early leavers from education and training in the selected regions in Bulgaria (7.1 per cent), Finland (4.5 per cent) and Spain (5.5\%), while in higher educational attainment Austria (17.3 per cent), Bulgaria (19.8 per cent) and Spain (14.7 per cent) display large differences compared to the rest of the countries. Concerning the youth unemployment rate, the largest regional differences are observed among regions in Austria (10.1 per cent), Bulgaria (12.1 per cent), Italy (13.8 per cent), Spain (14.4 per cent) and the UK (11 per cent). Based on the larger cross-regional differences and to ensure representation of different skill formation regimes ${ }^{10}$ we provide in-depth analysis for the following cases: Austria (collective regime), Bulgaria (Eastern liberal regime), Finland (statist regime), Spain (Southern liberal regime) and Scotland (as part of the UK) (liberal regime).

As pointed out earlier in this section, the skill formation regimes literature still takes nation states as the unit of analysis for international comparisons. While education and training systems tend to be designed and monitored at national level, their enactment and implementation takes place in socioeconomically varying regions within a country. Labour market characteristics (e.g. employment opportunities, industries, sectors, firms' size) vary across regions within a nation state. This cross-regional variation influences the opportunities and outcomes of people living in the region, including young adults in vulnerable situations. Hence, the effectiveness of national LLL policies addressed to young adults in vulnerable situations is likely to be influenced by regional labour markets, which is precisely the focus of this research.

\section{Data and methods}

We select Austria, Bulgaria, Finland, Spain and Scotland (as part of the UK) for in-depth case studies, as these represent different types of skill formation regimes and display socioeconomically contrasting regions within the country. We employ a qualitative approach to identify and discuss the varying effectiveness of LLL policies on youth employment across regions with different labour market demands, our main hypothesis being that regional labour markets moderate the effectiveness of these policies and, thus, youth employment. Three main methods have been used to address this objective: desk-based review of academic literature, semi-structured interviews with relevant actors (i.e. policy makers, employers' representatives, trade unions, 
skills agencies) involved in regional skill formation (49 in total, five per region on average) and a review of the grey literature (i.e. policy documents, reports) in the selected regions (65 documents in total, six to seven per region on average). ${ }^{11}$ The semi-structured interviews aimed at identifying the main regional challenges regarding LLL policies for young adults in vulnerable situations. The main areas covered in the interviews were the policy orientations of the interviewees' institutions, the regional governance of the skill formation system and the implications for young adults in the region. A qualitative content analysis of the texts (i.e. interview transcriptions and documents) has been applied using thematic coding to identify the main topics related to the regional skill formation systems (Bowen, 2009; Schreier, 2012). Seven coordinated research teams across the five countries under study replicated this exercise following the same analytical framework, data collection methods, analysis tools and reporting guidelines. The interviews were conducted between March and July 2017 and took place face to face where possible, while telephone or Skype interviews were conducted when the remoteness of the area or the availability of the interviewees required it. The results of the analysis for each region were summarised in national reports, which were used for the comparative report on which this chapter builds (Capsada-Munsech et al, 2018). The units of analysis are functional regions (FRs), as conceptualised by Klapka and colleagues (2013) and extensively discussed in Chapter 2 in this volume (Parreira do Amaral et al, 2019).

\section{Similar LLL policies, different regional labour markets}

Although there are clear differences in education and training systems among countries, inexistent or minor differences are observed across regions in the same country. Across the ten FRs under consideration, at least one institution has been identified that provides information to young adults on the educational and training options available. In most cases these are national institutions coordinated at the national level (e.g. Federal Ministry in Austrian FRs, Ministry of Education in Bulgarian FRs, Autonomous Community Agency for Vocational Education and Training and Labour Agency in Spanish FRs, National Skills Agency, Funding Council and Qualification Authority in the Scottish FRs); while the FRs in Finland are the only ones relying on regional and local institutions (i.e. regional councils and municipalities of Kainuu and south-west Finland). However, the skill formation challenges faced vary across regions within and between countries. Based on the interviews with relevant actors and stakeholders at the 
regional level, we identify a number of key issues in reference to the skill formation system that affect young adults' education and training opportunities in the region, especially relevant to those who find themselves in vulnerable situations.

One of the commonalities identified across all regions under study is that beyond the national education and training institutions and policies, the cross-regional differences in skill formation challenges are very much influenced by regional labour market demands. Across all FRs, interviewees pointed out that one of the most relevant objectives of the skill formation system targeting young adults - and especially those in vulnerable situations - is providing education, training and skills valued in the regional labour market. Only in two FRs out of ten (i.e. Glasgow FR, south-west Finland FR) were other purposes of skill formation for young adults explicitly mentioned (i.e. social inclusion, self-esteem, mental health). Given this strong focus on education, training and skills for work, two common policies have been identified across most regions concerning skill formation: apprenticeships schemes and employability training courses.

\section{When apprenticeships are not the solution}

Across countries and regions under study, apprenticeships are regarded as a good work-based learning policy to introduce young adults into the world of work. However, their relevance differs across regions depending on the type and level of skills demanded in the regional labour market. Moreover, their effectiveness is also influenced by their degree of development.

In the FRs with underdeveloped apprenticeship systems, interviewees identify this lack of development as one of the main causes of youth unemployment in the region. As mentioned by an interviewee in the FR of Blagoevgrad (Bulgaria), the assumption is that a more developed VET system, including a greater share of work-based learning, would improve youth's practical skills and equip them with the type of skills employers are looking for:

During the training in vocational schools and university it is necessary to have more apprenticeships and internships to support the formation of practical skills of young people. (WP_6E_BG_B_1)

The limitations of the apprenticeships (i.e. lack of vacancies and quality assurance) are not usually taken into consideration in initial stages 
of their implementation, but they emerge in countries and regions where this policy has a more long-standing history. In Aberdeen FR (Scotland, UK) one of the consequences of the 2014 oil and gas crisis - the most relevant economic sector in the region - has been the scarcity of available apprenticeship vacancies, as a nonnegligible number of apprenticeship positions became redundant. The result is that young adults in the most vulnerable situations (e.g. lower soft skills levels and/or limited social networks) are left without a work placement. As expressed by one of the interviewees in the region:

The main challenges at the moment are created by the downturn in oil and gas. For the first time in many, many years there are much less opportunities for young entrants to the labour market, whether it's through graduate level entry, apprenticeship entry or trainee-led entry. There has been a large scale number of redundancies and that's obviously impacted on the number of opportunities for youngsters. (WP6_E_UK_ACAR_2)

Similarly, in the FRs of Vienna (Austria) there are not enough apprenticeship vacancies available to place all students. In Austria, the value of attaining and gaining an apprenticeship certificate goes beyond technical and practical skills: employers recognise it as a proof of being able to commit to work and engage in a working culture. In Vienna FR concerns have also been directed towards the quality assurance of the VET system and how to monitor the process. As stated by one of the interviewees 'If you do not want to devaluate the apprenticeship system somebody has to assess it' (WP6_E_AT_V_3). Most apprenticeships in the region are hosted by small and medium enterprises in the service sector, which are already struggling with quality assurance and might consider withdrawal from the apprenticeship system if quality control increases. However, the Austrian government is concerned about the quality of this practical training. As expressed by one of the policy makers in the region:

The Chamber of Commerce operates the apprenticeship as an authority and there are major problems in terms of quality assurance. Because they just do not want us to make any regulations or introduce new quality assurance tools. [...] There are very few industrial apprenticeships in Vienna. They are all in the commercial or service sector. Those 
which are hosted by small businesses, they are confronted with a big quality problem from our point of view. Because we consider the apprenticeship a very, very useful training, the quality has to be secured. (WP6_E_AT_V_1)

Unsurprisingly, the young adults in more vulnerable situations are the ones most likely to end up in lower-quality apprenticeship positions or without one, as employers are more eager to train those perceived as the best:

There is a big fight for a certain group of young people. Actually, everyone wants to have the best ones from the beginning. We will see if this is getting a bit more relaxed with the young refugees who have come. However, the companies want the most capable ones and vocational schools too. (WP6_E_AT_V_1)

It is interesting to see how the relevance and concerns about apprenticeships have been pointed out in FRs with a comparatively high share of youth with higher education in the country. For instance, in Bulgaria the share of higher educated youth is 19.8 per cent higher in Blagoevgrad FR compared to Plovdiv FR. Similarly, Vienna FR outpaces Upper Austria FR by 17.3 per cent in the proportion of higher educated; in Scotland the proportion of higher educated youth is 5.8 per cent higher in Aberdeen FR than in Glasgow FR. The only country under study in which regional interviewees have not explicitly manifested any concerns about the apprenticeships is Finland, where both FRs (i.e. Kainuu and south-west Finland) present a similarly high proportion of youth with higher education. One of the interviewees in south-west Finland (WP6_E_FI_SF_3) pointed out that firms have usually considered apprenticeships as additional training to the schoolbased vocational training, and youth below the age of 25 are not the main target group for apprenticeships.

From a comparative perspective, these findings reinforce the idea that apprenticeships are more widely available in skill formation regimes with high involvement from employers. However, the relevance of these apprenticeships is questioned in regions with a highly educated labour force and a significant demand of high skills from the regional labour market. Moreover, the effectiveness of the apprenticeship model seems to decrease in periods of economic recession or when the predominant economic sectors go through difficulties, resulting in a limited offer of work placements. 


\section{Employability courses: training for what jobs?}

Although employability training courses designed and promoted at the national level allow for regional flexibility to adapt these to regional labour market demands, the strong focus on the (re)training of youth to move them into employment has not always taken into consideration the varying quantity and quality of employment opportunities across regions. As illustrated in the following paragraphs, the effectiveness of employability training is questioned in regions where there are limited - or even non-existent - employment opportunities for young adults. Moreover, in some regions the predominance of a specific industry or sector providing precarious employment also raises concerns about the appropriateness of training youth for these jobs. In addition to this, in some of these cases employability training seems to compensate for the limited degree of firms' involvement in youth's training.

Among the countries under study, it is not surprising that this type of employability training policy is more widespread across countries where there is a more limited involvement of firms in the skills formation system. However, as pointed out by some of the interviewees in these regions, this usually suggests changing labour market needs, scarce employment opportunities for youth or unattractive working conditions in the region (i.e. temporary contracts, low-skilled and low-waged work). In turn, these situations raise the question whether it is desirable to tailor the regional employability training courses to meet this type of labour market need. More specifically, in the Finnish FR of Kainuu there are concerns with reference to the necessary time frame and resources to develop new programmes to meet regional employment needs:

It can take years to change the machine that produces degrees. Creating new vocational study programmes takes years. And then the question is: what about the teaching staff? Which are their skills? Who would be the teachers in the new study programmes? What happens to the old teachers? (WP6_E_FI_K_3)

Likewise, an interviewee from the Spanish FR of Málaga (WP6_E_SP_MA_1) states that there is a time gap between the moment a study survey of training/employers' needs takes place and the training is up and running, leading to discrepancies between the available training and the regional labour market needs. However, in this Spanish FR, characterised by a high percentage of youth 
unemployment, these employability training courses are also used as a way to get early leavers from education and training back into the education and training system. Still, education and training is regarded as the main solution to the problem of young people's unemployment:

We attributed content to the 'professional certificates' to make them comparable to formal education. It is, thus, a useful certified training, which facilitates the later incorporation to the formal education system. Therefore, the main idea of this training is that those that did not have a formal qualification get it at the end of the training and it helps them progress either to further education or in their career. (WP6_E_SP_MA_1)

Let's imagine a 19-20-year-old boy who left education and training and who wants to later reenter into the system. He could retake it from there [i.e. employability training courses] and later upgrade to higher levels. (WP6_E_SP_MA_2)

Similar concerns about meeting the needs of a regional labour market arise across FRs that have a predominant employment sector, such as the oil and gas industry in Aberdeen FR, tourism in Girona and Málaga (Spain), metal and wood in Kainuu and automobile and marine industries in south-west Finland. Tailoring the employability courses to meet the needs of these specific industries or sectors facilitates youth employment in the region. Nevertheless, employment dependence on specific industries or sectors might also have negative consequences for young adults and the region, like the low-skilled but plentiful tourism sector jobs in Girona and Málaga FRs or the difficult working conditions of the metal and wood industries in Kainuu FRs. Moreover, the dependence on a single regional industry or sector of the economy makes youth more vulnerable to exogenous changes (e.g. the oil and gas crisis in Aberdeen FR) and might promote unbalanced demographic structures in terms of gender and age. However, as suggested by an interviewee in Finland, the voice of employers usually makes a stronger case than that of young adults:

It is a fact that the standpoints and opinions of certain actors and interest groups are more influential than those of the others when decisions are made. I can easily imagine that on the ongoing VET-reform the voice of students' organisations has not been heard as loud as the voice of 
the labour market organisations or the Ministry. Who has the money, has the power as well. (WP6_E_FIN_NAT_3)

Similarly, FRs with a predominant urban area (e.g. Girona FR, Glasgow FR, Vienna FR) are poles of attraction for high-skilled demand especially in the business and information and communications technology sectors - but these also coexist with a contrasting share of low-skilled demand - especially in the service sector. As stated by one of the interviewees in Girona FR:

There is still a lot of work to be done in transforming the hotel industry into a rigorous, formal, monitored productive sector providing appealing training and mid-term careers for people. (WP6_SP_GI_1)

Some of the interviewees in these urban FRs wonder how desirable it is from a public perspective to meet the regional labour demands of low-skilled jobs. From a short-term perspective, it might raise youth's employment figures, but also trap them in low-skilled jobs in the long run.

Finally, a cross-cutting topic raised across all FRs is: Who is responsible for developing youth's transferable communication and discipline skills? Beyond technical knowledge and skills, employers appreciate and require youth who can effectively communicate, behave and follow orders, as well as commit and have positive attitudes towards work. As suggested by an interviewee in the Finnish FR of Kainuu:

Many times the employers are not looking for someone who already knows everything, but they look for a suitable type, one who is nice to work with and one that can show they are able and willing to learn. (WP6_E_FI_K_1)

In like manner, in the Spanish FRs employers and policy makers refer to this type of youth as the ones "who love their work and what they do' (WP6_E_SP_MA_3) and 'who are motivated to work' (WP6_E_SP_GI_9). Employers consider these to be employability skills and would appreciate these being developed as part of employability training. However, many interviewees across FRs question the assumption that LLL policies supported with public funds should be responsible for promoting these skills. The main argument is that it would attribute legitimacy to employers' demands in relation to the lack of 'maturity' of young candidates and their 
limited working experience, which are usually unrealistic. An example of these concerns in the Blagoevgrad FR follows:

I think that sometimes employers have high expectations to the qualifications and experience of young people who are at the beginning of their professional career and are about to improve. (WP6_E_BG_B_2)

However, as one of the interviewees in Aberdeen FR pointed out, employers are not always sure about what they need:

There's the kind of disconnect between the employers' expectations, particularly with young people, and it's often based on prejudice and a lack of awareness of young people's degree of working experience. So, one of the things that struck me when I joined [the organisation] was that employers were quite quick to tell me what they didn't like, but were less quick to tell me what they actually needed. And very often that was based on perceptions of young people; the views of what they didn't like were based on perception rather than reality. (WP6_E_UK_ACAR_3)

In sum, the promotion at the national level of employability training courses aiming to meet regional labour market demands is not always feasible and/or desirable from a youth employment perspective. In regions with limited employment opportunities for young adults, the effectiveness of these policies is uncertain. Alternative policy solutions designed to redirect young adults into the formal education and training system seem more adequate in these cases. Conversely, in some regions the existence of employment opportunities does not necessarily mean that these are desirable from a social perspective. If the only available opportunities are precarious forms of employment, it is arguable to what extent public policies should be supporting training in these sectors.

\section{Conclusions}

The main LLL policy responses to the high youth unemployment rates in the European countries and regions under study have been delivered in the form of apprenticeships and employability training courses. The comparative analysis shows how existing typologies of skill formation regimes adequately capture institutional differences in terms of 
education and training provision. The clearest example is the wide availability of the apprenticeship offer in countries where employers are highly involved in training. However, the effectiveness of these schemes vary in terms of time and space. The changing economic cycle affects the capacity of companies to offer work placements to young adults. Additionally, the configuration of regional labour markets affects the level and the structure of the skills demanded (intermediate vs high skills). In the case of employability training courses, the influence of regional labour markets is even more important than in the case of apprenticeships. The effectiveness of this type of training courses is largely questioned in regions where the availability of jobs is scarce and/or the working conditions are very precarious. Investing a large sum of public funds in training for jobs that do not exist or that do not offer decent living conditions to their employees does not seem the most reasonable policy option. Our findings point out the importance of considering the regional/local level in comparative research, in particular because labour market demand impacts the effectiveness of LLL policies. Therefore, we can conclude that the 'supply-side fundamentalism' that has dominated European LLL agendas is not helping national and regional governments to support young adults in vulnerable situations to transition from education to the world of work, and that the inclusion of demand-side factors at the regional level should be taken into account to promote more effective LLL policies.

\section{Notes}

1 NUTS stands for Nomenclature of Territorial Units of Statistics of the European Union. See Table 5.1 for detailed correspondence between the FRs under study and NUTS 2. The YOUNG_ADULLLT project focused on the following countries: Austria, Bulgaria, Croatia, Finland, Germany, Italy, Spain, Portugal and Scotland (UK).

2 Data on public spending is unavailable for Croatia.

3 See Table C 1.3 in https://static.rasset.ie/documents/news/2017/09/oecd. pdf. This indicator is not available for Croatia.

4 Since no specific data for Scotland is available, we use data for the United Kingdom as a whole.

5 No data available for Bulgaria and Croatia.

6 No data available for Croatia.

7 Early leavers from education and training (Eurostat, 2014a): share of 1824 year olds who have completed at most lower secondary education and are not currently involved in any further education or training at NUTS 2. We use it as a proxy of the low-skilled youth supply at the regional level. 
8 Population with higher education attainment (Eurostat, 2014b): share of the population aged 30-34 with higher educational attainment (ISCED 5-8) at NUTS 2. We use it as a proxy of the high-skilled youth supply at the regional level.

9 Youth unemployment rate (Eurostat, 2014c): people aged 15-24 without employment and actively looking for a job at the national and NUTS 2 levels. Data corresponding to 2014, except for Bremen (2011) and northeast Scotland (2015). We use it as a proxy for the demand/labour market opportunities at the regional level.

10 None of the countries under study in the YOUNG_ADULLLT project can be classified in the segmentalist skill formation regime.

11 See Tables 5 and 6 in the annex of the WP6 - International Report analysis of skill supply and demand for a detailed list of interviewees' affiliation and grey literature reviewed (http://www.young-adulllt.eu/ publications/working-paper).

\section{References}

Allmendinger, J. (1989) 'Educational systems and labour market outcomes', European Sociological Review, 5(3): 231-50.

Ashton, D., Sung, J. and Turbin, J. (2000) 'Towards a framework for the comparative analysis of national systems of skill formation', International Journal of Training and Development, 4(1): 8-25.

Biesta, G. (2006) 'What's the point of lifelong learning if lifelong learning has no point? On the democratic deficit of policies for lifelong learning', European Educational Research Journal, 5(3-4): 169-80.

Bol, T. and van de Werfhorst, H. G. (2013) 'Educational systems and the trade-off between labor market allocation and equality of educational opportunity', Comparative Education Review, 57(2): 285-308.

Bowen, G. A. (2009) 'Document analysis as a qualitative research method', Qualitative Research Journal, 9(2): 27-40.

Busemeyer, M. R. and Iversen, T. (2012) 'Collective skill systems, wage bargaining, and labor market stratification', in M. R. Busemeyer and C. Trampusch (eds) The Political Economy of Collective Skill Formation, New York: Oxford University Press, pp 205-33.

Busemeyer, M. R. and Trampusch, C. (2012) The Political Economy of Collective Skill Formation, New York: Oxford University Press.

Capsada-Munsech, Q., Valiente, O., Bouillet, D., Palumbo, M., Cossetta, A., Pandolfini, V. and Ganter do Otero, J. P. (2018) 'WP6 International report comparative analysis skills supply and demand', YOUNG_ADULLLT Project Report. 
Crouch, C., Finegold, D. and Sako, M. (2001) Are Skills the Answer? The Political Economy of Skill Creation in Advanced Industrial Countries, New York: Oxford University Press.

Eurostat (2012a) 'Participation/enrolment of students at ISCED level 3-VOC - as \% of all students at ISCED level 3', http://appsso. eurostat.ec.europa.eu/nui/show.do?dataset=educ_ipart_s\&lang=en. Accessed 27 July 2018.

Eurostat (2012b) 'Public expenditure on education by education level and programme orientation - as \% of GDP', http://appsso.eurostat. ec.europa.eu/nui/show.do?dataset=educ_uoe_fine06\&lang=en. Accessed 27 July 2018.

Eurostat (2014a) 'Early leavers from education and training (\%) (aged 18-24) by sex and NUTS 2 regions, 2014', http://appsso.eurostat. ec.europa.eu/nui/show.do?dataset=edat_lfse_16\&lang=en. Accessed 27 July 2018.

Eurostat (2014b) 'Population aged 30-34 by educational attainment level, sex and NUTS 2 regions (\%)', http://appsso.eurostat.ec.europa. eu/nui/show.do?dataset=edat_lfse_12\&lang=en. Accessed 27 July 2018.

Eurostat (2014c) 'Unemployment rates by sex, age and NUTS 2 regions (\%)', http://appsso.eurostat.ec.europa.eu/nui/show.do?dataset=lfst_r_ lfu3rt\&lang=en. Accessed 27 July 2018.

Greinert, W. D. (2004) 'European vocational training “systems”: Some thoughts on the theoretical context of their historical development', European Journal: Vocational Training, 32: 18-25.

Hillage, J. and Pollard, E. (1998) 'Employability: Developing a framework for policy analysis', Department for Education and Employment, Research Brief, 85.

Klapka, P., Halás, M. and Torney, P. (2013) 'Functional regions: Concept and types', 16th International Colloquium on Regional Sciences, Masarykova Univerzita, Brno.

McGrath, S., Needham, S., Papier, J., Wedekind, V., Attwal, H. and Calitz, M. (2010) 'Employability in the college sector: A comparative study of England and South Africa', Department for Business Innovation \& Skills and British Council Report.

McQuaid, R. W. and Lindsay, C. (2005) 'The concept of employability', Urban Studies, 42(2): 197-219.

McQuaid, R. W., Green, A. and Danson, M. (2005) 'Introducing employability', Urban Studies, 42(2): 191-5. 
Parreira do Amaral, M., Lowden, L., Pandolfini, V. and Schöneck, N. (2019) 'Coordinated policy-making in lifelong learning: Functional regions as dynamic units', in M. Parreira do Amaral, S. Kovacheva, and X. Rambla (eds) Lifelong Learning Policies for Young Adults in Europe: Navigating between Knowledge and Economy, Bristol Policy Press, pp 21-44.

Peck, J. and Theodore, N. (2000) 'Beyond "employability", Cambridge Journal of Economics, 24(6): 729-49.

Pilz, M. (2016) 'Typologies in comparative vocational education: Existing models and a new approach', Vocations and Learning, 9(3): 295-314.

Saar, E., Ure, O. B. and Holford, J. (2013) Lifelong Learning in Europe, New York: Edward Elgar Publishing.

Schreier, M. (2012) Qualitative Content Analysis Practice, Thousand Oaks, CA: SAGE Publications.

Shavit, Y. and Müller, W. (1998) From School to Work: A Comparative Study of Educational Qualifications and Occupational Destinations, Oxford: Clarendon Press. 